\title{
Eating disorders in school children
}

\author{
João E.M. Vilela1, Joel A. Lamounier2, Marcos A Dellaretti Filho3, \\ José R. Barros Neto ${ }^{4}$, Gustavo M. Horta ${ }^{3}$
}

\begin{abstract}
Objective: To determine the prevalence of possible eating disorders and inappropriate eating behaviors in school children from six municipalities in the state of Minas Gerais, Brazil.

Methods: Cross-sectional study. The Bulimic Investigatory Test of Edinburgh (BITE), Eating Attitude Test (EAT), and Body Image Test were applied to 1,807 public school students with age ranging from 7 to 19 years.

Results: According to the EAT, 241 students (13.3\%), mostly females, had inappropriate eating behaviors. Nineteen students $(1.1 \%)$ had a BITE score indicating a possible diagnosis of bulimia nervosa. We found that 1,059 students (59\%) were unhappy with their body image; 731 students ( $40 \%)$ were on a diet; and 1,014 (56\%) exercised to loose weight. In addition, 218 students (12\%) presented binge-eating and 175 students (10\%) used purgative methods to control weight.

Conclusions: We observed a high prevalence of possible eating disorders and inappropriate eating behaviors in the study population, especially among female adolescents. These results are similar to those reported for developed countries. The present findings are relevant for the clinical care of children and adolescents and can serve as the basis for future works aimed at increasing our understanding of the risk factors for these illnesses.
\end{abstract}

J Pediatr (Rio J). 2004;80(1):49-54: Anorexia nervosa, bulimia nervosa, inappropriate eating behaviors, epidemiology.

\section{Introduction}

Anorexia nervosa and bulimia nervosa often are chronic eating disorders associated with high comorbidity. ${ }^{1}$ Bulimia is more frequent than anorexia, with a prevalence of 90 to $95 \%$ among females. ${ }^{2}$ Although the prevalence of these disorders in the general population usually is quite lower, an increase in the

1. Doctoral student, Universidade Federal de Minas Gerais (UFMG), Belo Horizonte, MG, Brazil.

2. PhD. Associate professor, Department of Pediatrics, School of Medicine, UFMG, Belo Horizonte, MG, Brazil.

3. Medical student, Faculdade de Ciências Médicas de Minas Gerais (FCMMG), Belo Horizonte, MG, Brazil.

4. Medical student, School of Medicine, UFMG, Belo Horizonte, MG, Brazil. Financial support: FAPEMIG, CNPq.

Manuscript received Jun 13 2003, accepted for publication Oct 012003. number of new cases has been observed in men and women in all age groups. According to several authors, the prevalence of these eating disorders (between 1 and $41 \%$ ) has remarkably increased in the last few years. ${ }^{3-7}$

Anorexia nervosa, first described in 1667,8 is a disease that leads to inanition with excessive selfinflicted weight loss and with great physical and psychological distress. Due to a distorted body image, individuals with anorexia nervosa do not see themselves as thin, and therefore continue to restrict their diet in a methodical way. ${ }^{9}$ Prepubertal patients may show delayed sexual maturation, delayed physical development, growth retardation, and may not achieve their target height. Anorexia nervosa has serious complications that result from malnutrition, such as cardiovascular involvement, 
dehydration, electrolytic disorders, gastrointestinal motility disorders, infertility, hypothermia, and other signs of hypometabolism. ${ }^{1-9}$ Fisher reports that the presence of amenorrhea is an important characteristic of anorexia nervosa, being associated with a combination of factors such as hypothalamic dysfunction, stress, excessive exercises, and weight and fat loss. ${ }^{10}$

Differently from anorexia, bulimia nervosa does not result in a greatly depleted nutritional status. Bulimic patients often maintain a near-normal weight or sometimes are slightly overweight, alternating between bouts of hyperphagia and self-induced vomiting. ${ }^{3}$ The distortion of body image usually is less pronounced than that observed in anorexia nervosa. ${ }^{11}$ The major complications of bulimia are electrolytic disorders, irritation, gastroesophageal bleeding, intestinal disorders, erosion of the dental enamel, and enlarged parotid glands. Resting bradycardia, hypotension, and reduced metabolic rate are observed in some bulimic patients, possibly indicating reduced activity of the sympathetic nervous system and of the thyroid axis. 1,2,10

Albeit yet unknown, the etiology of eating disorders is provably associated with social, psychological, and biological factors. ${ }^{2}$

The fact that our culture venerates women with a slim body is related to an increase in the occurrence of such disorders. Even though cultural factors, especially the drive for thinness, are extremely important, one should not forget that anorexia was first described at a time in which the stereotype of female beauty used to be a far cry from today's slim standards.

There are several psychological hypotheses that attempt to explain inanition as an etiologic factor of these eating disorders. There appears to be a consensus between these theories that eating disorders act as a form of psychological deterrent by interrupting the physical development of these adolescents, taking them to the prepubertal stage. ${ }^{12-15}$

With regard to genetic factors, several studies suggest that females who have anorexic relatives have a greater propensity for anorexia. According to the literature review conducted by Woodside, based on twin studies, the inheritability of anorexia and bulimia corresponds to 75 to $80 \%$ and 45 to $55 \%$, respectively. ${ }^{16}$ Some studies suggest cross-transmission of these disorders, with predominance of environmental factors in bulimia and genetic factors in anorexia. 17

The existence of an underlying hypothalamic dysfunction as the key to the symptoms of eating disorders seems unarguable. On the other hand, controversy still exists over whether this dysfunction is primary or secondary, and if secondary, whether it results from a nutritional deficit or emotional one, or from both. 10,18

According to most authors, eating disorders are more prevalent in industrialized countries, but several studies show that these disorders constitute a public health problem in developing countries as well. ${ }^{19,} 22$ The aim of the present study is to investigate the eating behavior of children and adolescents, as well as to determine the prevalence of eating disorders, not only of anorexia and bulimia, but also of clinically relevant eating disorders, since there is a paucity of studies in the Brazilian literature on this issue with this age group. 23,25

\section{Methods}

Students regularly enrolled in public schools of five municipalities of the state of Minas Gerais, Brazil, were interviewed. The selected municipalities/districts Dionísio, Inhaúma, Bom Jesus, Nossa Senhora do Carmo and Ipoema are small-sized, with a population between 3,000 and 5,000 inhabitants. Lectures were given in order to explain the aims of the study; the students were invited to participate in the study, and all of them accepted. The study included all students, aged between 7 and 19 years old, enrolled in the public schools of these towns (a total of 1,921 students). Students younger than seven years old and older than 19, or those who were enrolled in private schools, were not included. A loss of approximately $6 \%$ occurred, which corresponds to those students who did not complete all the tests. The final sample consisted of 1,807 students, 887 males and 920 females.

The data were collected by fifth-year undergraduate students of the School of Medicine of Minas Gerais between March 1998 and November 1998. Training sessions were held in order to prepare the researchers for the application of the tests, with the aim of obtaining greater homogeneity and resolving possible doubts. As self-rating scales were used, the researchers were very careful not to induce the answers. The following scales were used:

Eating Attitudes Test (EAT): developed by Garner \& Garfinkel ${ }^{26}$ initially as a diagnostic test for anorexia nervosa, but nowadays used to detect eating disorders in general. The results obtained showed that this test was not appropriate as a diagnostic tool, but that it was good at detecting clinical cases in high-risk populations and identifying individuals with an abnormal preoccupation with their diet and weight. Of the original 40 items in the scale, the authors decided to leave out 14 , as they were considered to be redundant and did not increase predictive power. The new scale, EAT-26, is simpler and more economic, being highly correlated with the original scale. A cutoff point of 20 was used.

Bulimic Investigatory Test Edinburgh (BITE): developed by Henderson and Freeman 27 to detect bulimic episodes and the factors related to cognition and behavior of bulimic individuals. This test may be used as an epidemiological tool for the identification of subclinical cases of bulimia and to monitor the outcome of patients and determine their response to the treatment used. The BITE is divided into two subscales: symptoms and severity. 
- Symptom Subscale: Assessment of symptoms, eating behavior, and diet; those with a score between 10 and 19 are considered to have a somewhat unusual eating behavior and not to meet all the criteria for the diagnosis of bulimia; those with a score higher than 19 show a high level of eating disorder, with the presence of bulimic episodes, and high risks for bulimia nervosa.

- Severity Subscale: Assessment of the severity of eating disorders based on their frequency; those with a score equal to or greater than 5 show significant severity, and those with a score greater than 9 have a high level of severity.

Body Image Test ${ }^{28}$ : individuals are shown several images of bodies that range in size from extremely thin to obese. They are asked to choose the image that best resembles their own body. After that, they are asked to indicate which body image they would like to have. The discrepancy between the two images shows how dissatisfied individuals are with their bodies. The body image test used herein consists of five images. In addition to choosing from the five images, the students could choose an imaginary image, which gives a total of nine options.

The collected data were coded and imported into a statistical program (Epi-Info 6.04). The basic statistical analysis and interpretation were made using the same program.

The questionnaire did not contain any information that allowed identifying the students. Participants gave their verbal consent and the schools also authorized the study.

\section{Results}

Among 1,807 students, 887 (49.1\%) were male and $920(50.9 \%)$ were female, with an age range between 7 and 19 years old (mean age of $12.7 \pm 2.5$ years). The distribution of the final sample among the towns was as follows: Ipoema: 494 students (27.3\%), Bom Jesus: 488 students (27\%), Dionísio: 347 students (19.2\%), Nossa Senhora do Carmo: 263 students (14.6\%), and Inhaúma: 215 students (11.9\%).

As to the Eating Attitudes Test (EAT), 241 students $(13.3 \%)$ had a score equal to or greater than 20 , that is, these students probably have subclinical eating disorders. There was a female predominance $(p=0.003)$ (Table1). Of these 241 students, only $43(17.8 \%)$ showed purging behaviors, indicating that such behaviors are significantly more frequent $(p=0.000)$ in possible cases of bulimia nervosa $(74 \%)$.

The BITE revealed 19 students $(1.1 \%)$ with a score equal to or greater than 25 , which corresponds to a possible diagnosis of bulimia; seven $(36.8 \%)$ of these students were male and $12(63.2 \%)$ were female, and all of them were older than 10 years. According to the symptom subscale, 296 students $(16.4 \%)$ had an average score (10 to 19), showing a somewhat unusual eating behavior, and 10 students had a high score (above 19), which indicates a probable diagnosis of bulimia nervosa. There was a nonsignificant female predominance both in the average score $(p=0.06)$ and high score $(p=0.79)$. According to the severity subscale, 188 students (11.8\%) reached the cutoff point $(=5)$, with basically no gender predominance (Table 1 ).

Table 1 - Prevalence of students according to EAT-26 and BITE scores

\begin{tabular}{|c|c|c|c|c|c|}
\hline Scores & Female & Male & $\chi^{2}$ & OR (95\% CI) & $\mathbf{p}$ \\
\hline EAT-26 & $145(60 \%)$ & $96(40 \%)$ & 9.10 & $1.54(1.16-2.05)$ & $<0.01$ \\
\hline \multicolumn{6}{|l|}{ BITE } \\
\hline Total & $12(63 \%)$ & $7(37 \%)$ & 0.71 & & $>0.05$ \\
\hline \multicolumn{6}{|l|}{ Symptom } \\
\hline mean score & $166(56 \%)$ & $130(44 \%)$ & 3.54 & & $>0.05$ \\
\hline high score & $6(60 \%)$ & $4(40 \%)$ & 0.07 & & $>0.05$ \\
\hline Severity & $93(49 \%)$ & $95(519 \%)$ & 0.12 & & $>0.05$ \\
\hline
\end{tabular}


We found 1,059 students (59\%) dissatisfied with their body images, of whom $511(48 \%)$ would like to be thinner and 548 (52\%) would like to be fatter. Among the students who would like to be thinner, $69 \%$ were female and $31 \%$ were male $(p=0.000)$. Among those who would like to be fatter, there was a significant male predominance $(p=0.000)$. Also, we found 731 students $(40 \%)$ who usually went on some kind of diet, with a significant female predominance $(p=0.000)$. Of these 731 students, only $118(16 \%)$ went on a diet regularly, while the remaining ones did so sporadically. Some people engage in physical activity to lose weight. In our sample, 1,014 students ( $56 \%$ ) did exercises in order to lose weight, with a remarkable female predominance ( $p$ $=0.000)$. Around $12 \%$ of the students had bulimic episodes, and once again, there was a female predominance $(p=0.003)$. Purging was used by $10 \%$ of the students (Table 2 ).

\section{Discussion}

The present study showed a prevalence rate similar to that reported by other countries, according to EAT and BITE scales. The prevalence rate of the BITE scale is approximately 1 to 1.54 (22.27) in most studies; in our study, the prevalence rate was $1.1 \%$. The same occurs with the EAT scales, whose prevalence is 6 to $13 \%$ 29-31 according to several studies; in our study, we found a rate of $13.3 \%$. Although eating disorders were significantly more frequent among women, we found a high prevalence among males, showing that these disorders have actually increased among men in the last few years. 1,2,9,10

The abuse of laxatives, self-induced vomiting, pills, and diuretics was quite common among students with a possible diagnosis of bulimia; self-induced vomiting was the most widely used method, observed in $73.34 \%$ (11 students) of the students with a possible diagnosis of

Table 2 - Prevalence of students according to the eating behavior

\begin{tabular}{|c|c|c|c|c|c|}
\hline Behavior & Female & Male & $\chi^{2}$ & OR (95\% IC) & $\mathbf{p}$ \\
\hline \multicolumn{6}{|l|}{ Body dissatisfection } \\
\hline Total & $598(56 \%)$ & $461(44 \%)$ & 31.06 & $1.72(1.41-2.08)$ & $<0.001$ \\
\hline Would like to be thinner & $355(69 \%)$ & $156(31 \%)$ & 97.16 & $2.94(2.35-3.68)$ & $<0.001$ \\
\hline Would like to be fatter & $243(44 \%)$ & $305(56 \%)$ & 13.21 & $1.46(1.19-1.80)$ & $<0.001$ \\
\hline \multicolumn{6}{|l|}{ Diet } \\
\hline Total & $426(58 \%)$ & $305(42 \%)$ & 26.14 & $1.65(1.36-2.00)$ & $<0.001$ \\
\hline Regularly & $62(53 \%)$ & $56(47 \%)$ & 0.07 & & $>0.05$ \\
\hline Sporadically & $364(85 \%)$ & $249(82 \%)$ & 26.10 & $1.68(1.37-2.05)$ & $<0.001$ \\
\hline Bulimic episodes & $132(61 \%)$ & $86(39 \%)$ & 8.78 & $1.56(1.16-2.10)$ & $<0.01$ \\
\hline \multicolumn{6}{|c|}{ Physical activity to lose weight } \\
\hline Total & $566(56 \%)$ & $448(44 \%)$ & 21.80 & $1.57(1.29-1.90)$ & $<0.001$ \\
\hline Regularly & $255(60 \%)$ & $171(40 \%)$ & 17.38 & $1.61(1.28-2.01)$ & $<0.001$ \\
\hline Sporadically & $311(53 \%)$ & $277(47 \%)$ & 1.25 & & $>0.05$ \\
\hline \multicolumn{6}{|l|}{ Purging behaviors } \\
\hline Total & $87(50 \%)$ & $88(50 \%)$ & 0.06 & & $>0.05$ \\
\hline Pills & $22(52 \%)$ & $20(48 \%)$ & 0.00 & & $>0.05$ \\
\hline Laxatives & $26(43 \%)$ & $34(57 \%)$ & 1.13 & & $>0.05$ \\
\hline Diuretics & $18(50 \%)$ & $18(50 \%)$ & 0.00 & & $>0.05$ \\
\hline Vomiting & $21(57 \%)$ & $16(43 \%)$ & 0.31 & & $>0.05$ \\
\hline
\end{tabular}


bulimia nervosa. Among the students at high risk for anorexia, only $13 \%$ showed some purging behaviors. This is consistent with the results of clinical trials, which indicate that such behaviors are much more frequent in cases of bulimia nervosa.

As far as age is concerned, the peak prevalence among students with a high score for eating disorders occurred in the 11-16 age group, early adolescence and at the beginning of the mean, 32 which is in agreement with other studies that report a higher prevalence of these disorders in adolescents. 33

The present study is one of the first publications about eating disorders involving Brazilian children and adolescents, and was carried out with communities in the rural area of the state of Minas Gerais, a lower prevalence rate was expected because we believed that regional sociocultural factors would be more preserved, acting as a possible protective mechanism due to the increased family and social interaction. However, we found rates that were as high as those reported by other studies, contradicting the findings of some studies, as the one conducted by Hoek, ${ }^{34}$ which advocate that the prevalence of these disorders may vary with the level of urbanization of the studied region. The prevalence rates are lower in underdeveloped regions, especially that of bulimia. Nowadays, the increase of globalization may have a negative impact on the population's eating habits and consequently increase the incidence of eating disorders.

\section{Acknowledgments}

We thank the following undergraduate students of the School of Medicine of Minas Gerais: Leandro L. Ticle, Fabricio L.S. Coutinho, Flávio J. Reis, Gustavo O. Ribeiro, Júlio S. Vasconcelos, Paulo R. Carvalho, Marcos L. P. Fereira.

\section{References}

1. Herzog DB, Sacks NR, Keller MB, Lavori PW, Ranson KB, Gray HM. Patterns and predictors of recovery in anorexia nervosa and bulimia nervosa. J Am Acad Child Adolesc Psychiatry. 1993;32:835-42.

2. Abott DW, Ackerman SH, Agras WS, Banzhaf D, Barber J, Bartlett JC, et al. Practice guideline for eating disorders. Am J Psychiatry. 1993;150:212-24.

3. Mirandé G, Celada J, Casas JJ. Prevalence of eating disorders in spanish scholl-age population. J Adolesc Health. 1999;24:212-19.

4. Szmukler GI. The epidemiology of anorexia nervosa and bulimia. J Psychiatr Res. 1985;19:143-53.

5. Theander S. Anorexia nervosa: a psychiatric investigation of 94 female case. Acta Psychiatr Scand. 1970;214:1-9.

6. Willi J, Grossman S. Epidemiology of anorexia nervosa in a defined region of Switzerland. Am J Psichiatry. 1983;140:564-7.

7. Jones JM, Bennett S, Olmsted MP, Lawson L, Rodin G. Disordered eating attitudes and behaviours in teenaged girls: a schoolbased study. CMAJ. 2001;165:547-52.
8. Silverman JA. Historical development. In: Halmi KA, editor. Psychobiolology and Treatment of Anorexia Nervosa and Bulimia Nervosa. 1st ed. Washington: American Psychiatric Press; 1993. p. 3-17.

9. Mahan LK, Stump SE. Nutrição na adolescência. In: Mahan KL, Escott-Stump S, editores. Krause - Alimentos, Nutrição e Dietoterapia. 9a ed. São Paulo: Roca; 1998. p. 279-283.

10. Fisher M, Golden NH, Katzman DK, Kreipe RE, Ress J, Schebendach J, et al. Eating disorders in adolescents: a Background Paper. J Adolesc Health. 1995;16:420-37.

11. Williams SR. Equilíbrio de energia e manejo do peso. In: Fundamentos de Nutrição e Dietoterapia. $6^{a}$ ed. Porto Alegre: Artes Médicas; 1997. p. 91-113.

12. Ajuriaguerra J. Manual de Psiquiatria Infantil. $5^{\mathrm{a}}$ ed. Barcelona: Toray-Masson; 1976.

13. Bruch $\mathrm{H}$. Anorexia nervosa. Theory and therapy. Am J Psychiatry. $1982 ; 139(12): 55-63$.

14. Crisp AH, Norton K, Gowers S, Haleck C, Bowyer C, Yeldham D, et al. A controlled study of the effect of therapies aimed at adolescent and family psychopathology in anorexia nervosa. $\mathrm{Br}$ J Psychiatry. 1991;159:325-33.

15. Nunes MAA, Abuchain ALG. Anorexia nervosa: quadro clínico, critério diagnóstico e etiologia. J Bras Psiquiatr. 1995;44 Supl $1:$ S5-9.

16. Woodside DB. A review of anorexia nervosa and bulimia nervosa. Curr Probl Pediatr. 1995;25:67-89.

17. Strober M. Family-genetic studies. In: Psychobiology and Treatment of AN BN. 1st ed. Washington: Halmi; 1993. p. 61-76.

18. Lópes-Mato AM, Ciprian-Ollivier J, Cetkovich-Bakmas M. Anorexia nervosa, bulimia y otros transtornos de la alimentación. Su ecuadre dentro el concepto de disorexia central. In: CiprianOllivier J, editor. Psiquiatria Biológica Fundamentos y Aplicación Clínica. $1^{a}$ ed. Buenos Aires: Científica Interamericana; 1988. p. 110-120.

19. Oyewumi LK, Kazarian SS. Abnormal eating attitudes among a group of Nigerian youths: I. Bulimic behaviour. East Afr Med J. 1992;69:663-6.

20. Wlodarczyk-Bisaga K, Dolan B. A two-stage epidemiological study of abnormal eating attitudes and their prospective risk factors in polish schoolgirls. Psychol Med. 1996;26:1021-32.

21. Lee $Y H$, Rhee MK, Park SH, Sohn CH, Chung YC, Hong SK, et al. Epidemiology of eating disordered symptoms in the Korean general population using a Korean version of the Eating Attitudes Test. Eat Weight Disord. 1998;3:153-61.

22. Ghazal N, Agoub M, Moussaoui D, Battas O. Prevalence of bulimia among secondary school students in Casablanca. Encephale. 2001;27:338-42.

23. Feijo RB, Sukster EB, Friedrich $L$, Fialho $L$, Dziekaniak KS, Christini DW, et al. Estudo de hábitos alimentares em uma amostra de estudantes secundaristas de Porto Alegre. Pediatria (São Paulo). 1997;19:257-62.

24. Vilela JEM, Lamounier JA, Oliveira RG, Ribeiro RQC, Gomes ELC, Barros Neto JR. Avaliação do comportamento alimentar em crianças e adolescentes de Belo Horizonte. Psiquiatr Biol. 2001;9:121-30.

25. Dunker KLL, Philippi ST. Hábitos e comportamentos alimentares de adolescentes com sintomas de anorexia nervosa. Rev Nutr. 2003; 16:51-60.

26. Garner DM, Garfinkel PE. The Eating Attitudes Tests: an index of symptoms of anorexia nervosa. Psychol Med. 1979;9:273-9.

27. Henderson $M$, Freman CPL. A self-rating scale for bulimia: the "BITE". Br J Psychiatry. 1987;150:18-24.

28. Thompson JK. Assessment of body image. In: Allison DB, editor. Handbook of Assessment Methods for Eating Behaviors and Weight-Related Problems: Measures, Theory and Research. 1st ed. Thousand Oaks, California: Sage Publications; 1995. p. 119-48.

29. Nakamura K, Hoshino Y, Watanabe A, Honda K, Niwa S, Tominaga $\mathrm{K}$, et al. Eating problems in female Japanese high school students: a prevalence study. Int J Eat Disord. 1999;26:91-5.

30. Ballester FD, De Gracia BM, Patino MJ, Sunol GC, Ferrer AM. Eating attitudes and body satisfaction in adolescents: a prevalence study. Actas Esp Psiquiatr. 2002;30:207-12.

31. Neumark-Sztainer D, Croll J, Story M, Hannan PJ, French AS, Per C. Ethic/racial differences in weight-related concerns and behaviors among adolescent girls and boys: findings from Project EAT. J Psychosom Res. 2002;53:963-74. 
32. Ferreira RA, Romanini MAV, Miranda SM, Beirão MMV. Adolescente: particularidades de seu atendimento. In: Leão E. Pediatria Ambulatorial. $3^{a}$ ed. Belo Horizonte: COOPEMED; 1998. p. 49-57.

33. Marchi M, Cohen P. Early childhood eating and adolescent eating disorders. J Am Acad Child Adolesc Psychiatry. 1990;29:112-17.

34. Hoek HW. The incidence and prevalence of anorexia nervosa and bulimia nervosa in primary care. Psychol Med. 1991; 21(2):455-60.
Corresponding author:

João Eduardo Mendonça Vilela

Rua Samuel Pereira, 260/1402

CEP 30310-550 - Belo Horizonte, MG, Brazil

Tel.: + 55 (31) 3287.6667/3223.2389

Fax: +55 (31) 3223.2197

E-mail: jemvilela@uai.com.br 